\title{
A dimensão política na formação dos profissionais de saúde
}

| ${ }^{1}$ Carolina Pereira Lobato, ${ }^{2}$ Regina Melchior, ${ }^{3}$ Rossana Staevie Baduy |

Resumo: São necessários avanços na implementação do SUS no Brasil. Os trabalhadores da saúde são agentes instituintes de mudança nas práticas do mundo do trabalho. O presente artigo buscou compreender algumas possibilidades para contemplar a dimensão política na formação desses trabalhadores. O território de estudo foi um programa de residência multiprofissional em saúde no interior de São Paulo. Para a produção dos dados, além de observação, foram realizadas 14 entrevistas semiestruturadas com residentes, preceptores, tutores e com a coordenação do programa. A análise foi dividida em potências para a dimensão política nas práticas pedagógicas e nas práticas de gestão da Residência. Encontraram-se potências nos espaços pedagógicos, de gestão e no mundo do cuidado. As tensões dispararam um processo de autoanálise nos sujeitos envolvidos e propiciaram novos arranjos no processo formativo. Evidenciou-se que as residências podem ser dispositivos para a formação de trabalhadores da saúde na defesa do SUS.

Palavras chave: Educação; residência não-médica; poder; educação permanente em saúde; educação continuada; relações de poder.

\author{
1 Apoiadora Institucional \\ da Coordenação Geral de \\ Gestão da Atenção Básica do \\ Departamento de Atenção \\ Básica do Ministério da Saúde, \\ Brasília-DF. Endereço eletrônico: \\ carolina.p.lobato@gmail.com \\ 2 Professora Associada do \\ Departamento de Saúde \\ Coletiva da Universidade \\ Estadual de Londrina, doutora \\ em Saúde Pública pela \\ Faculdade de Saúde Pública \\ da USP. Endereço eletrônico: \\ reginamelchior@gmail.com \\ ${ }^{3}$ Professora Adjunta do \\ Departamento de Saúde \\ Coletiva da Universidade \\ Estadual de Londrina, \\ Doutorado em Programa \\ de Pós-Graduação pela \\ Universidade Federal do Rio de \\ Janeiro. Endereço eletrônico: \\ robaduy@gmail.com
}


É no contexto da produção de novos sujeitos e coletivos para a garantia de um sistema público de saúde que este texto se insere. A implementação do SUS precisa avançar; para tanto, processos educativos coerentes com a mudança no fazer profissional se fazem necessários. Para que os trabalhadores da saúde sejam, na assistência, no ensino ou na gestão, agentes instituintes de mudança nas práticas do mundo do trabalho, outras estratégias e referenciais devem ser considerados na sua formação (FEUERWERKER, 2005). Assim, apresenta-se neste artigo a dimensão política como um desses referenciais.

São várias as interpretações sobre o reconhecimento da dimensão política nos processos educativos. Neste artigo, fala-se da dimensão política que reconhece as relaçôes de poder e as disputas existentes entre os principais atores envolvidos na formação dos trabalhadores: docentes e residentes. É na dimensão política que a função social do trabalhador e das instituições formadoras é explicitada e pode ser debatida, sendo lugar de disputa dos projetos de saúde e sociedade postos em pauta pelos sujeitos do processo educativo.

Contemplar a dimensão política na formação dos trabalhadores pode implicar mudanças na formação de sujeitos, capazes de desencadear um "movimento de forças criativas, mobilizando energias e propostas inovadoras" (MALTA; MERHY, 2003, p. 64). Novas conformações organizacionais, mais democráticas, podem colaborar na produção de novos sujeitos e coletivos, mais comprometidos éticopoliticamente, e que possam agir como agentes micropolíticos da construção do SUS (CAMPOS, 1997; MERHY, 2002).

Uma das propostas para formar profissionais para uma atuação diferenciada no SUS é a educação no e pelo trabalho. Trataremos, assim, de alguns elementos para o debate da dimensão política da formação dos trabalhadores, tendo como foco as Residências Multiprofissionais em Saúde como uma das propostas de educação pelo trabalho. Os novos conceitos que se agregam a essa modalidade de formação propõem outras diretividades aos processos educativos, centradas nas necessidades de saúde da população, no trabalho em equipe multiprofissional e na institucionalização da Reforma Sanitária Brasileira.

Com o estabelecimento de financiamento regular para os Programas Multiprofissionais em Saúde, a partir da implantação da Política de Educação Permanente em 2004 (BRASIL, 2006), nos últimos anos, vários segmentos 
envolvidos com a formação dos trabalhadores da saúde e dos Programas de Residências Multiprofissionais em Saúde inseriram seus projetos e entendimentos sobre essa modalidade de especialização no cenário nacional de formação dos profissionais de saúde.

Este estudo objetivou compreender de que maneira a Residência Multiprofissional em Saúde da Família pode contemplar a dimensão política na formação dos trabalhadores.

\section{O território escolhido para o estudo}

Com a grande diversidade de Programas de Residência Multiprofissional no Brasil, a escolha do território para a realização do estudo se deu a partir da indicação de uma das formuladoras da Política Nacional de Educação Permanente, referência para o tema das Residências Multiprofissionais no Brasil. Ao conhecerem-se os pressupostos teóricos do currículo, apresentados por Oliveira (2006), entendemos que o programa reunia características potencializadoras da dimensão política da formação dos trabalhadores: garantia de espaços de reflexão sobre a prática; "diversificação de cenários e forte estímulo à capacidade de aprender a aprender e do trabalho em equipe" (p. 125); relação do programa de residência com os movimentos de mudança nos cursos de graduação e na rede de serviços; e busca pela relação horizontal entre os sujeitos envolvidos em um processo construtivista baseado na aprendizagem significativa e de adultos (OLIVEIRA, 2006).

O programa estudado está vinculado a uma universidade federal e desenvolve suas atividades na rede pública de serviços de saúde do município. Com duração de dois anos e carga horária de 60 horas semanais, os residentes vivenciam o atendimento à população nas unidades básicas de saúde com supervisão de tutores e preceptores. Dispõem, ainda, de tutoriais que os auxiliam na reflexão sobre a prática com facilitadores de aprendizagem, bem como de reuniões com a comunidade ou segmentos organizados da sociedade (profissionais da Secretaria Municipal de Saúde), e de reuniōes mensais com a equipe da coordenação.

$\mathrm{O}$ curso, em sua primeira turma, ofereceu 46 vagas, preenchidas por oito enfermeiros, oito cirurgiōes-dentistas, cinco terapeutas ocupacionais, cinco fisioterapeutas, cinco psicólogos, cinco educadores físicos, cinco assistentes sociais e cinco nutricionistas. Os preceptores eram docentes da universidade e profissionais de saúde da Secretaria Municipal de Saúde, numa relação de um preceptor para cada 
cinco residentes. Os tutores enfermeiros e dentistas do programa eram profissionais de saúde que trabalhavam nas Unidades Básicas de Saúde do município, numa relação de um tutor por residente. Para as outras categorias, os tutores seriam profissionais qualificados, identificados pela universidade e pela Secretaria Municipal de Saúde, numa relação de um tutor para cada cinco residentes.

\section{A escolha dos instrumentos para a produção dos dados e sua análise}

$\mathrm{Na}$ chegada ao território, percebeu-se que os encontros entre o pesquisador e as singularidades do lugar indicariam os caminhos para a produção dos dados. A pergunta era: como compreender o processo educativo num território vivo e dinâmico?

Logo nos primeiros dias de vivência, nas aspiraçôes metodológicas pretendeuse participar de todos os espaços educativos formais dos residentes, além de interagir nos espaços deliberativos institucionalizados no programa. Mas, devido à paralisação das atividades dos residentes, eles não aconteceriam no período da vivência. A paralisação foi motivada pelo atraso no pagamento das bolsas e na retomada das atividades assistenciais e pedagógicas depois do recesso de final de ano. Os residentes do segundo ano aguardavam definições sobre o término do curso e havia incertezas sobre a continuidade do programa.

Ao pensar nas discussões acerca das dificuldades de estudar os fenômenos qualitativos, especialmente nas ciências sociais e humanas, põe-se em pauta a "ditadura do método" sobre a realidade, que considera real apenas o que cabe em um método de captação e mensuração (DEMO, 1998). Bichuetti, Oliveira e Amorin (2004) afirmam que a pesquisa, hegemonicamente reconhecida, é espaço de emersão de regularidades, de leis gerais, de causalidades, de normas, isto é, modo de funcionar do instituído que perpetua a hegemonia e obscurece a diferença, as multiplicidades, os devires que são imanentes ao próprio real e pulsam gerando acontecimentos, o genuinamente novo.

Foram 45 dias de vivência institucional. Muitos acontecimentos, muitas possibilidades de encontros. Propôs-se, então, superar a pseudo-neutralidade do sujeito epistêmico, e durante a vivência, abrir-se às ressonâncias, ao acaso, ao diferente, aos acontecimentos de um território vivo. Entendeu-se que, na medida em que há afetação com o território, com os encontros, faz-se 
parte da sua produção. Propôs-se experimentar a cartografia, pois ela celebra

formas diferenciadas de se fazer-pensar os territórios e permite acompanhar os acontecimentos na constituição do mundo (DELEUZE; GUATTARI, 1995; ROLNIK, 2006). Rolnik (2006, p. 23) afirma que a cartografia, diferentemente do mapa - representação de um todo estático -, "é um desenho que acompanha e se faz ao mesmo tempo que os movimentos de transformação da paisagem".

Para a produção dos dados, além das 14 entrevistas semiestruturadas com alguns sujeitos do programa, fizeram parte do corpus os diários de campo, produtos da imersão no território, relatos dos acontecimentos, dos encontros, de suas potências e de seu funcionamento. Buscaram-se, também, nos documentos oficiais do programa (manuais e termos de referência) as intenções pedagógicas de tal formação.

Das 14 entrevistas, duas foram realizadas com a coordenação e a vicecoordenação do curso, com três dos 24 tutores (02 de enfermagem e 01 de odontologia), e quatro dos 15 preceptores (01 da medicina, 01 da terapia ocupacional, 01 da psicologia e 01 da educação física). Foram enviados e-mails para todos os integrantes do programa. A escolha dos interlocutores foi intencional, acolhendo o interesse de participação no estudo. Para os preceptores e tutores, elencaram-se os que tinham vinculação ao programa desde o seu início ou que participassem dos espaços deliberativos da Residência. Dos 46 residentes, cinco manifestaram interesse em colaborar com o estudo: dois residentes de fisioterapia, um nutricionista, um enfermeiro e um terapeuta ocupacional.

Nas entrevistas, foi utilizado o mesmo roteiro para preceptores, tutores, residentes e coordenação do curso. Foram seis perguntas abertas que abordaram a trajetória acadêmica e profissional dos entrevistados, as diferenças percebidas entre a formação dos trabalhadores nas residências e em outras especializações lato sensu e a contribuição da residência na formação de profissionais críticos e reflexivos. Além desses assuntos, os entrevistados foram questionados sobre se, em seu entendimento, o programa contemplava a dimensão política na formação.

Para se chegar aos territórios de análise, fez-se uma leitura cuidadosa das entrevistas e dos diários de campo. Dessa forma, os territórios de análise não foram escolhidos a priori: resultaram da escuta dos ruídos e dos "silenciamentos" produzidos pelos sujeitos nas entrevistas, pelos diários de campo da pesquisadora, além dos escritos compartilhados pela coordenação do curso. 
O projeto da pesquisa foi aprovado pelo Comitê de Ética em Pesquisa envolvendo seres humanos da Universidade Estadual de Londrina (UEL) com o parecer $n^{\circ} .198 / 2008$.

\section{Referencial teórico utilizado nos territórios de análise}

Sabe-se que há vários entendimentos sobre o uso do poder dentro das instituições e diversas abordagens sobre o tema. Entretanto, é com o conceito de poder cunhado por Foucault que este estudo dialogou. Para o autor, o poder é algo difuso e dinâmico, pois relativiza a ideia dos dominadores e dominados. É “[...] o jogo que, através de lutas e afrontamentos incessantes, as transforma, reforça, inverte" (FOUCAULT, 1988, p. 88). Deve, assim, ser analisado no seu exercício, na correlação de forças, na sua micropolítica (FOUCAULT, 1979) e em seus efeitos "periféricos". Machado (2002), escrevendo sobre Foucault, afirma que "o poder não existe; existem, sim, práticas ou relações de poder. O que significa dizer que poder é algo que se exerce, que se efetua, que funciona” (p. XIV).

Para melhor compreensão da vivência institucional, os dados produzidos foram agrupados em dois territórios de análise: potências para a dimensão política na prática pedagógica e no espaço de gestão. Em cada um deles, buscou-se caracterizar e evidenciar suas potências para a politicidade de sujeitos, trabalhadores da saúde em processo de formação. A politicidade é entendida como:

a habilidade humana de saber pensar e intervir, no sentido de atingir níveis crescentes de autonomia individual e coletiva. [...] [É] menos a capacidade de alargar limites dados do que a habilidade de se confrontar com limites impostos. [...] [T] rata-se de processo interminável de conquista, como é a participação (DEMO, 2002, p. 11).

Pretendeu-se, no programa de residência vivenciado, destacar as tensões do processo educativo, buscando problematizar os desarranjos e novos arranjos de produção de realidade que provocaram mudanças macro e micropolíticas no território e em seus sujeitos.

Apresentam-se, a seguir, os territórios de análise do estudo. Buscou-se compreender, nos modos de formar e de gerir, como a politicidade esteve presente no processo educativo em questão.

\section{Potências para a dimensão política na prática pedagógica}

Nas práticas educativas, a abordagem pedagógica está permeada deintencionalidade. Não sendo neutros, os diversos tipos de atos pedagógicos na formação dos 
trabalhadores da saúde - mesmo que não conscientes - manifestam-se em defesa

de projetos distintos de saúde e de sociedade. Há, portanto, escolhas feitas por quem elabora os projetos dos cursos, mas, sobretudo, por quem os coordena e conduz, além das pessoas que vivenciam os processos educativos, materializando suas escolhas, no cotidiano dos espaços micropolíticos das instituições.

Ao entender que, nas práticas educativas, a escolha pela abordagem pedagógica pode ser uma ferramenta potente para a dimensão política da formação do trabalhador, evidenciamos características que foram destacadas pelos sujeitos do território, pelos documentos normativos do programa e a partir dos encontros durante a vivência institucional.

Nos princípios educativos formalizados no manual do programa e nos discursos oficiais da coordenação, dos preceptores e tutores, a potência encontrava-se na organização curricular e na adoção da abordagem pedagógica construtivista, fundamentada na aprendizagem significativa e desenvolvida por meio de metodologias ativas de aprendizagem.

Várias são as aplicações do construtivismo. No ensino, Matui (1995) afirma que o construtivismo é "uma teoria do conhecimento que engloba numa só estrutura dois polos, o sujeito histórico e o objeto cultural, em interação recíproca, ultrapassando dialeticamente e sem cessar as construções já acabadas para satisfazer as lacunas ou carências (necessidades)” (p. 46). Nessa perspectiva, o programa de residência fundamentava-se na interação entre os sujeitos e na aprendizagem baseada na prática, a qual promove e produz sentidos no mundo do trabalho.

[...] é o residente como dispositivo central da formação. Isso faz muita diferença, porque aí ele tem que construir respostas, ele precisa de uma postura de construção, de invenção, de absolutamente atividade. [...] O dispositivo é o próprio sujeito. (Preceptor 3).

No processo educativo em questão, um dos principais espaços pedagógicos são os momentos de discussão da prática em pequenos grupos nas preceptorias de campo e de núcleo, além das tutorias realizadas no local de trabalho. Entendese que esses pequenos grupos são importantes para a expressão dos sujeitos. São espaços para sínteses coletivas e para o exercício de novas conformações da relação educador-educando, pois o residente, segundo o manual do programa, deve participar da exploração do problema, da busca e da análise crítica das informações, característica das metodologias ativas de aprendizagem. 
No entanto, isso depende, em parte, da mediação da aprendizagem. Na prática pedagógica dita construtivista, o educador é o mediador da discussão, sendo esta a ação que se interpõe entre o sujeito e o objeto de aprendizagem (MATUI, 1995). O reconhecimento desse papel pode potencializar a configuração da relação entre preceptor/tutor e residentes, secundarizando o papel "professoral" (e tradicional) daqueles. É o "professor" saindo da cena de detentor do saber para assumir uma postura dialógica com o grupo.

Nesta metodologia você tem que ter uma postura muito diferente, de estar numa relação horizontal, de possibilitar a palavra pro outro, de abrir pro conflito, de expor o conflito. (Preceptor 3).

[...] Antes morria de medo de ter conflito. Só que hoje tem que ter. Certamente, quando não há uma discussão, alguém não colocou o que pensava. [...] Na relação com o residente, você não tem que saber tudo. (Tutor 1).

Outra potência para a dimensão política, além da conformação desses pequenos grupos, está em como se dá a escolha dos temas geradores das discussões. Eles advêm do concreto, das práticas cotidianas dos residentes nas Unidades de Saúde da Família. Os disparadores do processo reflexivo são as questôes e os problemas da realidade. Isso contribui para a construção do conhecimento e também pode estimular os educandos na busca (individual e coletiva) da compreensão do contexto dos principais problemas de saúde e do processo de trabalho das equipes.

Para o sucesso disso, todos devem ser corresponsáveis pelas discussōes realizadas. $\mathrm{O}$ mediador de aprendizagem problematizador deve impulsionar o aprofundamento dos temas, estimulando o educando à busca, à reflexividade e à construção do conhecimento, pois pensar criticamente demanda profundidade na compreensão e na interpretação dos fatos (FREIRE, 1996).

As diferentes inserções no sistema durante a formação nas residências podem colocar os sujeitos do processo educativo em relaçôes (de poder e saber) diferenciadas. A cada turma surgem novas conformações, novos fluxos conectivos, novos saberes e poderes intervindo nos processos produtivos, podendo, assim, desencadear novos processos de subjetivação no mundo do trabalho.

Ampliei bastante minha visão na residência, pelo contato com outras categorias profissionais, outras formas de fazer, outros conceitos. Apesar de toda essa vivência gerar crise, revemos a própria prática. Fazer o enfrentamento de algumas situaçôes suas que eram bastante tradicionais, bastante tecnicistas. (Residente 4)

Como alternativa para o desenvolvimento de novos perfis profissionais, a residência proporcionou muitos encontros nos locais de produção de ações de 
saúde pela presença contínua dos residentes. Portanto, reforça-se a residência

multiprofissional como dispositivo de mudanças de práticas e potencializador da formação de agentes micropolíticos na construção do SUS, pois

os cenários de produção do cuidado, como cenários de produção pedagógica, ressignificam a educação na saúde e colocam-na para além da relação ensino-aprendizagem, mas no âmbito dos agenciamentos de cognição e subjetivação, com o sentido de criar grupos-sujeito capazes de assumir para si o protagonismo, sob certa intencionalidade, que determina o desenvolvimento do SUS. (FRANCO, 2007, p. 435)

Mais ainda, nas características da abordagem pedagógica, encontrava-se o sistema de avaliação no programa da residência. A avaliação mostrou-se tanto ferramenta de gestão, como instrumento de participação ativa de todos os envolvidos no processo educativo, com a finalidade de proporcionar a melhoria de processos e produtos dentro do programa. Residentes, preceptores, tutores, consultores e o próprio programa são avaliados tanto de maneira formativa (que busca a melhoria do processo ensino-aprendizagem) como de maneira somativa (alcance dos objetivos pré-estabelecidos, para uma determinada fase do programa), esta última sendo responsabilidade final dos preceptores.

O processo avaliativo dos residentes merece destaque. Segundo os documentos oficiais do programa, ele deve ser dialógico, por meio de um processo transparente e democrático que melhore não só os desempenhos individuais, mas o também o programa como um todo. A avaliação do residente deveria se dar de forma contínua e analisar o processo de desenvolvimento do trabalhador em formação através da elaboração conjunta do plano de melhorias (PM), espécie de projeto de competências/desempenhos a alcançar em um período de tempo. Evidenciariam-se, singularmente, as lacunas e os avanços de cada residente em formação, privilegiando não somente o produto, mas o processo de qualificação dos trabalhadores. Além dos planos de melhoria, baseados nos conceitos "satisfatório" ou "precisa melhorar", os residentes deveriam fazer, a cada semestre, avaliaçôes formativas (ao longo do processo de aprendizagem) e, ao final da residência, uma avaliação somativa.

\section{A entrega da prova em branco como analisador}

Muitas divergências em relação aos rumos do programa e ao entendimento da abordagem pedagógica emergiram durante a vivência. Em vários momentos, a qualidade dos espaços pedagógicos e dos processos avaliativos, além da compreensão 
1282 das metodologias ativas de aprendizagem, foram questôes evidenciadas como componentes importantes para a qualificação daquela formação.

Nos dias da produção dos dados, foi desencadeada uma mobilização dos residentes, que tinha em sua pauta a reestruturação dos espaços de ensinoaprendizagem e a inclusão do Coletivo de Residentes nas discussões pedagógicas. Os residentes queriam participar da gestão de seu próprio processo pedagógico. Dessa forma, definiu-se como instrumento de tensionamento para as mudanças na formação que todos entregariam em branco a primeira prova somativa. Com a manifestação, queriam discutir a concepção de avaliação e o formato da prova, já que a reunião em que isso seria feito havia sido cancelada.

Ao entrarem em contato com a prova, os residentes entenderam que, além de não privilegiar a integração do conhecimento adquirido no processo da residência, enfatizava-se a memorização de conceitos e conteúdos tecnicistas, numa prova desarticulada com a dimensão política do SUS. Ainda que esta não prescinda dos conhecimentos teórico e técnico, evidencia-se a necessidade de incluir novos referenciais para a prática educativa dos trabalhadores. É “[...] preciso tratar especificamente da questão do conteúdo e das práticas, porque elas não são decorrência automática de qualquer mudança metodológica" (FEUERWERKER, 2002, p. 29).

Por compreender que a avaliação é "um terreno estratégico de transformação dentro de uma proposta de mudança das relações e dos papéis desempenhados por professores e estudantes no processo ensino-aprendizagem" (FEUERWERKER, 2002, p. 42), traçaram-se algumas linhas de força que se apresentaram no território durante a vivência: as redes de poder e sua relação com o saber. Entendia-se que
o poder [...] não se ancora numa instituição, não se apoia em nada fora de si mesmo [...]; por isso, o poder é fugaz. O saber, bem ao contrário, se estabelece e se sustenta nas matérias/conteúdos formais que lhe são exteriores [...].É bem por isso, que o saber é apreensível, ensinável, domesticável, volumoso. E poder e saber se entrecruzam no sujeito, e não num universal abstrato.[...] [O] que opera esse cruzamento nos sujeitos é o discurso (VEIGA-NETO, 2003, p.157-158).

Dessa forma, a entrega da prova em branco evidenciou-se como analisador. Para Lourau (1975, p. 69), “é o analisador que realiza a análise”. É manifestação do instituído, acontecimento revelador e ao mesmo tempo catalisador, produto e produtor de situações. Segundo o autor, com base no conceito desenvolvido por Félix Guattari, "dar-se-á o nome de analisador àquilo que permite revelar a 
estrutura da instituição, provocá-la, forçá-la a falar” (LOURAU, 1993, p. 284, grifo do autor).

Por que escolheram a prova, legitimada na instituição "escola" para avaliar (ou punir?) os alunos, como objeto de tensionamento para a mudança de práticas no programa de residência? O que está em disputa nesse acontecimento?

Tal fato teve interpretaçóes divergentes entre os envolvidos no processo educativo, reforçando a polarização presente entre educadores e educandos:

Eles estão se colocando no nosso papel! Isso aconteceu pela liberdade com relação aos dois espaços e agora estamos colhendo os frutos. Demos muito espaço para essa formação política. (Preceptor 4).

A fala acima aponta para três elementos analíticos - "o saber" como exercício de poder; o "excesso de liberdade" como indisciplina e contravenção às normas, limites historicamente instituídos na relação educador-educando, e o "lugar do conflito" na formação desses trabalhadores.

Uma possibilidade interpretativa aproxima-se da discussão de que o saber é a concretização do (exercício do) poder no (ou através do) discurso, no caso, nos encontros entre sujeitos no cenário pedagógico. Além disso, compreende-se que o poder é um elemento capaz de explicar como se produzem os saberes e como nos constituímos na articulação entre ambos.

Nas entrevistas, afetadas pelos acontecimentos daqueles dias, alguns sujeitos ressaltaram a disciplina como elemento importante para a relação dos indivíduos dentro da instituição "escola":

Eu sou uma pessoa rebelde, mas sou muito disciplinada. Eu mudo regras, mas enquanto aquela for a regra, eu cumpro. Posso até lutar para mudá-la, mas eu não vou descumpri-la somente porque eu não concordo... isso é contravenção. Quem não fez a prova tirou zero, eles têm que aprender a lidar com seus atos e com as consequências. (Preceptor 4).

Contudo, sabe-se que muitos dos educadores foram formados nessa mesma escola, a qual captura, normaliza e subjetiva para a repetição. Na metodologia proposta pelo programa, primeira experiência de muitos, as dúvidas sobre o limite e a disciplina eram recorrentes na relação com a primeira turma de residentes:

A gente fica muito perdido com as ideias do que é limite, do que é responsabilidade, do que é autoridade, do que é autoritarismo. Como a metodologia é uma metodologia aberta, a relação horizontal deve acontecer. Mas quando há discordância, qualquer atitude pode ser chamada de abuso de poder, imposição, mas é diferente de autoritarismo. (Preceptor 3). 
Veiga-Neto (2003) aponta que a escola foi sendo concebida como a grande máquina de fazer dos corpos o objeto do poder disciplinar, e, assim, torná-los dóceis, mas ressalta que

isso não significa que ela fabrica corpos obedientes. Falar em corpos dóceis é falar em corpos maleáveis; mas não se trata de uma modelagem imposta, feita à força.[...] [O] que é notável no poder disciplinar é que ele 'atua' no nível do corpo e dos saberes do que resultam formas particulares tanto de estar no mundo - no eixo corporal quanto de cada um conhecer o mundo e nele se situar - no eixo dos saberes (p. 85).

Nessa direção, Foucault (1988), ao escrever sobre a História da Sexualidade, afirma que se é ela quem articula o corpo (indivíduo, comportamento corporal) com a população (unidade múltipla, efeitos procriadores), é a norma quem articula os mecanismos disciplinares (que atuam sobre o corpo) com os mecanismos regulamentadores (que atuam sobre a população). Assim, a norma é o elemento que

ao mesmo tempo que individualiza, remete ao conjunto dos indivíduos. [...] [N]este processo de individualizar, e ao mesmo tempo, remeter ao conjunto [...] chamam-se de anormais aqueles cuja diferença em relação à maioria se convencionou ser excessivo, insuportável. Tal diferença passa a ser considerada um desvio, isto é, algo indesejável porque des-via, tira do rumo. (VEIGA-NETO, 2003, p. 90)

Todavia, entende-se que seja necessário evidenciar que toda a relação de poder se dá entre diferentes e na diferença. O que percebemos na relação entre educandos e educadores, muitas vezes, é a tentativa de um exercício de poder desigual, em que não há espaço para o saber do outro, num processo de deslegitimação por não estar hierarquicamente autorizado a divergir das normas, das regras. $\mathrm{Na}$ diferença, o conflito deve ser encarado como disputa, como tensão, não como contravenção. São forças que disputam a direção, o sentido dos projetos, dos caminhos a percorrer. Dessa forma, entende-se o conflito como constitutivo dos coletivos, pois ele acontece nas relações, como "um pensamento que privilegia a ideia da diferença para instaurar novos ângulos e perspectivas do real" (VASCONCELLOS, 2005, p. 1.217).

Lins (2005, p. 1.234) propõe - ao contrário da maioria de sistemas educativos, assentados na representação - "pensar, imaginar, engendrar uma pedagogia dos possíveis, sem raízes, sem troncos, galhos ou folhas fundadores que dividem as coisas firmando a árvore como 'ato inaugural' de todo o processo educativo". Que seja "um encontro nômade e não uma palavra de ordem. Um conversar 
com no lugar de um falar sobre". Sugere "uma pedagogia da desconstrução e da diferença, do indivíduo como singularidade”, que proporciona abertura

à criação e às conexôes: desterritorialização e linhas de fuga. Rizoma, e não árvore. A árvore define o território, o crescimento vertical e a identidade do ser. O rizoma é horizontalidade que multiplica as relações e os intercâmbios que dele se originam. (LINS, 2005, p.1232).

No analisador proposto, a entrega em branco da avaliação formativa foi o artifício escolhido para desencadear a discussão sobre o processo pedagógico e, assim, buscar "novos possíveis". E, de fato, foi importante para instituir um espaço de diálogo e de escuta sobre as tensões daqueles dias e provocar mudanças no processo avaliativo.

\section{Potências para a dimensão política nos espaços de gestão}

Assim como na abordagem pedagógica e na escolha pela conformação dos espaços de aprendizagem, o funcionamento dos espaços de gestão do programa de residência pode manifestar como tem circulado o poder dentro da organização. Esse território de análise pode colaborar na discussão da dimensão política, pois, na configuração de arranjos estruturais, de linhas de produção de subjetividade e de métodos de gestão, é possível contribuir na constituição de sujeitos com maior capacidade de análise e intervenção sobre a realidade (CAMPOS, 2000).

Os espaços coletivos de exercício de democracia institucional, de correlação de forças e de confronto de projetos são alguns dos espaços de exercício de poder dentro das instituições (CAMPOS, 2000). Foram analisadas as potências dos respectivos espaços - "lugares e tempos por meio dos quais [...] [os sujeitos envolvidos no processo educativo] possam interferir nos sistemas produtivos" (p. 28).

Ressalta-se que o funcionamento desses espaços depende da compreensão dos sujeitos que o compõem frente ao exercício do poder e da gestão, podendo operar como legitimador de definições feitas alhures ou como lugar de elaboração de projetos, de formação de compromissos e de gestão de contratos.

A partir da vivência institucional, destacam-se alguns espaços coletivos existentes no programa: reuniões da Comissão da Residência Multiprofissional (COREMP), reuniōes da Equipe da Gestão e reuniōes do Coletivo de Residentes. A COREMP era composta pela coordenação e por representantes de tutores, preceptores e residentes: 

espaço-dispositivo que pode favorecer o desenvolvimento de uma postura crítica e ética. (Preceptor 3).

Trata-se de um lugar criado para ser o espaço deliberativo do programa. Porém, as discussões sobre as questóes pedagógicas eram realizadas pela equipe de gestão formada pelo grupo dos preceptores e pela coordenação. Alguns dos sujeitos mencionaram que a COREMP era um espaço estritamente político.

Além da comissão, os residentes tinham duas horas semanais para o encontro do próprio coletivo. Até os meses da vivência institucional, nenhum outro programa no país contemplava em sua carga horária espaço instituído para o encontro de residentes sem mediação da coordenação, do preceptor ou tutor. $\mathrm{O}$ coletivo era coordenado por residentes do primeiro e segundo anos. Ali, discutiam-se pautas da representação do programa e realizavam-se diversas atividades temáticas, com filmes, textos, atividades lúdicas e também de cunho político, como discussões do Movimento Nacional de Residentes e os rumos da Política Nacional e Local.

\section{Uma análise a partir da cogestão e da participação}

Foi proposto, então, analisar as potências dos espaços de gestão e participação nas dimensōes políticas da formação. Buscou-se compreender o funcionamento dos espaços coletivos e compreender como e por quem as decisōes eram tomadas e quais suas conexões. Entendeu-se que, para além dos espaços coletivos, o modelo de gestão se conforma nas relações, na forma como as decisões são percebidas e vivenciadas pelos sujeitos no cotidiano das instituições. Nesse sentido, durante a vivência, analisou-se, a partir de alguns espaços de decisão instituídos, como os sujeitos se relacionaram e tomaram decisôes a partir dos acontecimentos no território. Na experiência institucional, o funcionamento dos espaços coletivos foi um importante analisador para a compreensão das linhas de força no território. Um desses espaços foi a COREMP.

A partir da suspensão da reunião ordinária que seria realizada no final do ano de 2008 e que deliberaria sobre vários assuntos de interesse do programa, a legitimidade do principal espaço coletivo da residência foi posta em xeque. Os residentes levantaram como questão a centralização das decisões pela coordenação e pela equipe de gestão, formada também por preceptores. Ressaltaram, ainda, a importância de fortalecer a COREMP como espaço de negociação e definição 
dos rumos institucionais do programa com a participação de todos, visto que, ainda, a comissão era espaço de legitimação das propostas da Equipe de Gestão.

Entende-se que os espaços coletivos representativos, como os colegiados, sejam espaços de exercício da politicidade nas residências. Contudo, pensálos como única forma de participação pode restringir a potência da dimensão política desta formação.

Um preceptor, na reunião da Equipe de Gestão, identificou, a partir dos acontecimentos do território, que o grupo dirigente precisava reconhecer a ausência de espaços ampliados, para além dos espaços representativos, para discussão de problemas convergentes:

Nunca houve um encontro entre residentes e gestão do programa. [...] [E] m momento de crise, os fóruns de gestão do cotidiano não dão conta, devem ser ampliados. [...] $[\mathrm{P}]$ recisamos rever a forma como nos relacionamos. (Preceptor 3).

$\mathrm{Na}$ vivência, observou-se que são vários os entendimentos sobre gestão e participação. Alguns tutores e preceptores reconheceram a importância desta ser parte da formação dos sujeitos envolvidos no processo educativo. Guizardi e Pinheiro (2006) sugerem um movimento de inversão em relação ao tema da participação nos processos educativos: não se trata de formar para participar, mas de participar para formar. Assim, é necessário compreender o caráter formativo dos processos decisórios, reconhecer e expor os dispositivos de poder que restringem a capacidade de governo da coletividade, buscar instituir, nos processos formativos, espaços de encontro, de corresponsabilização, de solidariedade entre os sujeitos para que experienciem valores democráticos e universais.

Contemplar a dimensão política na formação dos trabalhadores implica mudanças na construção de sujeitos. E a

base dessa proposta de mudança é a democratização, um produto social que se constrói por meio da intervenção deliberada de sujeitos e que depende da correlação de forças, da mudança dos poderes instituídos, da capacidade de se construírem espaços de poder compartilhado (FEUERWERKER, 2002, p. 20).

Não haverá mudanças nas práticas de cuidado no SUS sem sujeitos desejantes de um sistema público de saúde fortalecido. Para tanto, deve-se considerar a dimensão política na formação dos trabalhadores da saúde, pois ela "inscreve-se na necessidade de escolher e afirmar determinados valores em detrimento de outros, o que constitui o cerne de toda atividade implicada na produção do mundo [...] e das relações que o configuram" (GUIZARDI; PINHEIRO, 2006, p. 369). 


\section{Considerações finais}

O estudo buscou caracterizar e evidenciar as potências do território para a politicidade de sujeitos, trabalhadores da saúde, em processo de formação em saúde da família em um programa de residência. No universo estudado, foi possível compreender que a dimensão política pode ser contemplada nos encontros, nas tensões entre os sujeitos durante o processo educativo nas relações, na prática pedagógica e nos espaços de gestão do programa. Através da experimentação do conflito, é possível aventurar-se na produção de novos sentidos, caminhando para uma pedagogia rizomática na prática educativa: da resistência, da diferença e da revitalização do instituído.

Nas relações nas práticas educativas, os sujeitos envolvidos no processo educativo reconheceram que a abordagem pedagógica e a escolha pela conformação dos espaços de aprendizagem foram componentes importantes para o exercício da politicidade durante a formação. A potencialidade encontrou-se na organização curricular e na adoção da abordagem pedagógica construtivista, fundamentada na aprendizagem significativa, desenvolvida por meio de metodologias ativas de aprendizagem. Os residentes, principalmente, ressaltaram seu papel ativo como componente importante para a construção do conhecimento na abordagem proposta pelo curso, afirmando que os assuntos necessários às mudanças de sua prática deveriam emergir do cotidiano dos serviços, do mundo do trabalho, além da necessária integração nas discussōes de seu próprio processo educativo.

Outro aspecto importante evidenciado foram os espaços de gestão do curso. Assim como na abordagem pedagógica e na escolha pela conformação dos espaços de aprendizagem, o funcionamento dos espaços de gestão do programa de residência pode manifestar como tem circulado o poder dentro da organização. Esses espaços mostraram potencialidades para o exercício da dimensão política, pois na configuração de arranjos estruturais, de linhas de produção de subjetividade e de métodos de gestão é possível contribuir na constituição de sujeitos com maior capacidade de análise e intervenção sobre a realidade. A cogestão, não deve ser compreendida como "o lugar" para a politicidade, mas como (permanente) tensão para a produção de novas formas de se relacionar, como modo de ser na organização. Não se buscou localizar o exercício do poder nos espaços coletivos, mas reconhecê-los como potenciais dispositivos para a produção de novos possíveis, 
de pertencimento às obras e ao território, de construção de si e das relações no e com o mundo, bem como importantes componentes para contemplar a dimensão política do trabalhador em formação.

Assim, a formação de trabalhadores da saúde, em novas conformações organizacionais mais democráticas e arranjos pedagógicos que garantam a horizontalidade no processo ensino-aprendizagem, como parece ter sido o programa em questão, pode auxiliar na produção de novos sujeitos e coletivos, mais comprometidos ético-politicamente, que ajam como agentes micropolíticos da construção do SUS, tanto para disputar a qualificação das práticas no mundo do cuidado como para tensionar a consolidação do SUS como política pública. ${ }^{1}$

\section{Referências}

BICHUETTI, J.; OLIVEIRA, M.F; AMORIN, M. Esquizoanálise e produção do conhecimento: o uso do esquizodrama na pesquisa. Monografia (Curso de Especialização em Análise Institucional e Esquizoanálise) - Instituto Felix Guattari, Unipac, Belo Horizonte, 2004. Disponível em: <http://www.fgbbh.org.br/artigos/esquizoanalise_e_producao. htm>. Acesso em: 02 abril 2009.

BRASIL. Introdução: a trajetória da residência multiprofissional em Saúde no Brasil. In: BRASIL, Ministério da Saúde. SGTES/DEGES. Residência multiprofissional em saúde: experiências, avanços e desafios. Brasília: Ministério da Saúde, 2006.

CAMPOS, G.W.S. Reforma da reforma. 2.ed. São Paulo: Hucitec, 1997. Um método para análise e co-gestão de coletivos. São Paulo: Hucitec, 2000.

DELEUZE, G.; GUATTARI, F. Milplatôs: capitalismo e esquizofrenia. v.1. Rio de Janeiro: Editora 94, 1995.

DEMO, P. Politicidade: razão humana. Campinas: Papirus, 2002.

FEUERWERKER, L.M. Além do discurso de mudança na educação médica: processos e resultados. São Paulo: Hucitec, 2002.

FEUERWERKER, L.M. Modelos tecnoassistenciais, gestão e organização do trabalho em saúde: nada é indiferente no processo de luta para a consolidação do SUS. Interface Comunic, Saúde, Educ, v.9, n.18, p.489-506, set-dez. 2005.

FOUCAULT, M. História da sexualidade 1: a vontade de saber. 16.ed. Rio de Janeiro: Graal, 1988.

. Microfísica do poder. 17.ed. Rio de Janeiro: Graal, 1979.

FRANCO, T.B. Produção do cuidado e produção pedagógica: integração de cenários no sitema de saúde no Brasil. Interface - Comunic, Saúde, Educ, v.11, n.23, p.427-438, set-dez 2007. 
FREIRE, P. Pedagogia da autonomia: saberes necessários à prática educativa. 36.ed. São Paulo: Paz e Terra, 1996.

GUIZARDI, F.L.; PINHEIRO, R. Participação política e cotidiano da gestão em saúde: um ensaio sobre a potencialidade formativa das relaçôes institucionais . In: PINHEIRO, R.; MATOS, R. Gestão em redes. Rio de Janeiro: Cepesc, 2006. p.369-384.

LINS, D. Mangue's School ou por uma pedagogia rizomática. Educação \& Sociedade. Campinas, v.26, n.93, p. 1.229-1.256, 2005.

LOURAU, R. A análise institucional. Petrópolis: Vozes, 1975. . Análise institucional e práticas de pesquisa. Rio de Janeiro: NAPE-UERJ, 1993.

MACHADO, R. Introdução: Por uma genealogia do poder. In: FOUCAULT, M. Microfísica do poder. 17.ed. Rio de Janeiro: Graal, 2002.

MALTA, D.C.; MERHY, E.E. A micropolítica do processo de trabalho em saúde: revendo alguns conceitos. Revista Mineira de Enfermagem. Belo Horizonte, v. 7, n. 1, p. 61-66, jan-jun 2003.

MATUI, J. Construtivismo: teoria construtivista sócio-histórica aplicada ao ensino. São Paulo: Moderna, 1995.

MERHY, E.E. Saúde: a cartografia do trabalho vivo. 2.ed. São Paulo: Hucitec, 2002.

OLIVEIRA, M.S. Inserção da Residência Multiprofissional em Saúde da Família e Comunidade no contexto da graduação dos cursos da área da saúde. In: BRASIL. Ministério da Saúde. SGTES/DEGES. Residência multiprofissional em saúde: experiências, avanços e desafios. Brasília: Ministério da Saúde, 2006. p. 123-140.

ROLNIK, S. Cartografia sentimental: transformações contemporâneas do desejo. Porto Alegre: Sulina, 2006.

VASCONCELLOS, J. A filosofia e seus intercessores: Deleuze e a não-filosofia. Educação \& Sociedade. Campinas, v.26, n. 93, p. 1.217-1.227, 2005.

VEIGA-NETO, A. Foucault e a educação. Belo Horizonte: Autêntica, 2003.

\section{Nota}

${ }^{1}$ C.P. Lobato participou da concepção original da pesquisa, da elaboração do projeto, da coleta dos dados, da análise dos dados e da elaboração do manuscrito. R. Melchior e R.S. Baduy participaram da concepção original da pesquisa, da elaboração do projeto, da análise dos dados e da elaboração do manuscrito. 


\section{Abstract}

\section{Political dimension in the education of health professionals}

Advances are needed in the implementation of the Unified Health System (SUS) in Brazil. Health workers are instituting agents of change in the practices of the working world. This paper aims to understand some possibilities to ponder on the political dimension in training these workers. The territory of study was a multidisciplinary health residence program in São Paulo. For data production, as well as observation, semistructured interviews were conducted with 14 residents, preceptors, mentors and program coordination. The analysis was divided into powers for the political dimension in teaching practices and management practices of the Residence. Powers were met in educational, management and world of care. Tensions created a process of self-examination in the subjects involved and provided new arrangements in the training process. It was evident that the residences can be devices for the formation of health workers in defense of SUS.

> Key words: Education; nonmedical internship; power; continuing education. 